\title{
Design of Wear-Resistant Austenitic Steels for Selective Laser Melting
}

\author{
J.N. LEMKE, R. CASATI, N. LECIS, C. ANDRIANOPOLI, A. VARONE, \\ R. MONTANARI, and M. VEDANI
}

Type 316L stainless steel feedstock powder was modified by alloying with powders containing carbide/boride-forming elements to create improved wear-resistant austenitic alloys that can be readily processed by Selective Laser Melting. Fe-based alloys with high $\mathrm{C}, \mathrm{B}, \mathrm{V}$, and $\mathrm{Nb}$ contents were thus produced, resulting in a microstructure that consisted of austenitic grains and a significant amount of hard carbides and borides. Heat treatments were performed to modify the carbide distribution and morphology. Optimal hard-phase spheroidization was achieved by annealing the proposed alloys at $1150{ }^{\circ} \mathrm{C}$ for 1 hour followed by water quenching. The total increase in hardness of samples containing 20 pct of C/B-rich alloy powder was of 82.7 pct while the wear resistance could be increased by a factor of 6 .

https://doi.org/10.1007/s11661-017-4461-7

(c) The Minerals, Metals \& Materials Society and ASM International 2018

\section{INTRODUCTION}

AUSTENITIC stainless steels are widely used in applications where a performance combining strength, toughness, and corrosion resistance is required. ${ }^{[1]}$ Wear resistance, on the contrary, is considered as a potentially critical issue for austenitic steels owing to their soft single-phase face-centred cubic crystal structure. There are several ways to increase the wear resistance of austenitic steels, including solid solution hardening (mainly by $\mathrm{Mn}$ and $\mathrm{N}$ ), cold plastic deformation and stress-induced transformation of austenite into martensite. ${ }^{[2-4]}$ A further approach consists in second-phase hardening, by additions of carbide/boride-forming elements. ${ }^{[5]}$ In the literature, information on potential improvement achievable in both austenitic and ferritic stainless steels by addition of $\mathrm{V},{ }^{[6]} \mathrm{Ti}$ and $\mathrm{Nb}^{[7]}$ and $\mathrm{B}^{[8,9]}$ is already available. Several applications of these materials would benefit from advanced wear performance such as in the processing industry and in the tool and die sectors. In these fields, additive manufacturing (AM) production techniques, allowing the generation of complex 3D shapes, are of particular interest (e.g., for the implementation of conformal cooling channels in tools).

J.N. LEMKE, R. CASATI, N. LECIS, and M. VEDANI are with the Dipartimento di Meccanica, Politecnico di Milano, Via Giuseppe La Masa 1, 20156, Milan, Italy. Contact e-mail: maurizio.vedani@polimi.it C. ANDRIANOPOLI is with the Cogne Acciai Speciali SpA, Via Paravera 16, 11100, Aosta, Italy. A. VARONE and R. MONTANARI are with the Dipartimento di Ingegneria industriale, Università degli Studi di Roma Tor Vergata, Via del Politecnico 1, 00133, Rome, Italy.

Manuscript submitted July 26, 2017.
Selective Laser Melting (SLM) is the main reference technology for AM, allowing the production of parts by an additive process, where a metallic alloy powder is deposited layer-wise and selectively melted by a laser source based on a CAD file. ${ }^{[10-12]}$

The processing of $316 \mathrm{~L}$ austenitic stainless steel by SLM has already been investigated in a large number of papers. Near full-density parts could be readily produced with the absence of flaws and showing attractive mechanical properties that can reach or even exceed those of wrought counterparts. ${ }^{[13-16]}$ Recent papers also focused on the modification of chemical composition of standard steel grades to improve properties and to achieve enhanced processability by SLM. ${ }^{11,17]}$ However, the number of studies on additively manufactured high-strength and tool steels containing significant amounts of carbon is still low and often it is stated that attempts to produce crack-free parts have been unsuccessful. Recent studies on steels processed by SLM and featuring a significant hardness obtained by carbide precipitation were focussed on X110CrMoVAl 8-2 alloy, ${ }^{[18]}$ on Fe-Cr-Mo-V-C alloy, ${ }^{[19]}$ on X40CrMoV5-1 (type H13) tool stee ${ }^{[20]}$ and even ultra-high carbon $(2,1$ wt pct) steel. ${ }^{[21]}$ The experiments showed promising results even if those steels are considered as critical in terms of processability due to their complex microstructure and brittleness.

In this study, a 316L steel grade was investigated. Compositional modifications were obtained by gradually increasing the amount of $\mathrm{C}, \mathrm{B}$, and of carbide/boride-forming elements, while maintaining the $\mathrm{Cr}: \mathrm{Ni}$ ratio nearly constant in order to keep a stable austenitic matrix as a prerequisite for good ductility and damage tolerance during processing and 
in service. A systematic study is presented in this paper by the investigation of a set of proposed alloys with increasing amounts of alloying elements, considering their SLM processability, microstructure, hardness and wear behavior.

\section{EXPERIMENTAL METHODS}

An AISI 316L stainless steel powder was used as master alloy. It was modified by the addition of increasing amounts of a C- and B-rich alloy also containing $\mathrm{V}, \mathrm{Nb}$, $\mathrm{Ti}$ as carbide and boride formers, hereafter labeled as CB alloy. Both powders had been produced by gas atomization and featured a spherical shape, with an average size of 31 and $32 \mu \mathrm{m}$ for the $316 \mathrm{~L}$ and the $\mathrm{CB}$ alloy, respectively. Powder morphology is shown in Figure 1, while the chemical compositions of the $316 \mathrm{~L}$ and $\mathrm{CB}$ alloys are given in Table I. Further estimates of the expected alloy compositions achieved by blending the above powders are also reported in Table I. Hereafter, the alloys obtained by blending the two powders will be designated by $316-\mathrm{xCB}$, where $\mathrm{x}$ represents the weight fraction of added $\mathrm{CB}$ alloy to the 316L steel matrix.

Powders were blended according to desired fractions given in Table I and mixed in a powder drum mixer by sealed containers at a rotational speed of $30 \mathrm{rpm}$ for 10 hours. The alloys were then processed by a prototype powder-bed device for laboratory-scale SLM tests. The device is composed of a multimode continuous wave active fiber laser (IPG Photonics YLP-1000), which is coupled to a scanner head (ElEn ScanFiber). The system operates in a sealed chamber under Ar gas. During the process, the laser beam selectively scans the surface of the powder layers. The distance between adjacent scan lines is controlled through the software of the scanner while the thickness of each deposited layer is defined by a motorized z-axis. The powder is laid down through a motorized rubber wiper.

Sample parts were built starting from a carbon steel substrate, using a mono-directional scanning strategy with the process parameters given in Table II. These SLM parameters have been set on the basis of preliminary tests. Cubic samples having sides of $5 \mathrm{~mm}$ were initially produced for microstructural analyses, whereas larger plates with a side of $18 \mathrm{~mm}$ and a thickness of $3 \mathrm{~mm}$ were used for wear tests.

Properties of the alloys were investigated in their as-built condition and after heat treatments. Annealing was performed at three different temperature levels of $1100{ }^{\circ} \mathrm{C}, 1150{ }^{\circ} \mathrm{C}$, and $1200{ }^{\circ} \mathrm{C}$ for 1 hour followed by water quenching to modify the carbides/borides precipitated during solidification.

Samples for microstructural investigations were sectioned at mid-thickness along different directions and subsequently grinded and polished according to standard metallographic procedures. A solution of nitric acid (65 pct), hydrochloric acid (35 pct), and water in a ratio $1: 1: 1$ was used to etch the samples for microstructure observation with a scanning electron microscope (SEM), equipped with an Inca Energy 200 energy dispersive X-ray (EDX) detector. Vickers hardness tests were performed using a load of $500 \mathrm{~g}_{\mathrm{f}}$ to evaluate changes in strength of the different investigated alloys as also affected by the thermal treatments.

Phase identification was carried out by X-ray diffraction (XRD) analyses. In particular, second phases were electrochemically dissolved and separately analyzed to improve detectability. A cell operating at room temperature with a solution of $\mathrm{HCl}(10 \mathrm{pct})$ in methanol was adopted for phase extraction featuring a platinum cathode, applied tension of $4 \mathrm{~V}$ and a current of $0.2 \mathrm{~A}$. The filtering of the extracted particles was performed using Durapore membrane with pores of $0.1 \mu \mathrm{m}$. XRD spectra were recorded by step scanning within a $2 \Theta$ angular range of 15 to 40 deg with steps of $0.05 \mathrm{deg}$ and a counting time of 2 seconds per step. Mo-K radiation $(\lambda=0.07093 \mathrm{~nm})$ was used.

Differential Scanning Calorimetry (DSC) analyses were performed in Ar atmosphere at a heating rate of $30{ }^{\circ} \mathrm{C} / \mathrm{min}$ on samples having a weight of about $50 \mathrm{mg}$ to investigate phase stability and melting temperatures of the alloys.

Finally, the wear resistance of the investigated materials was evaluated by a pin-on-disk type tribometer under dry sliding conditions, using an alumina pin loaded with a force of $2 \mathrm{~N}$. The samples were preliminarily ground and polished with alumina paste of $1 \mu \mathrm{m}$, cleaned in acetone and then tested at a speed of $0.10 \mathrm{~m} / \mathrm{s}$ for a sliding distance of $200 \mathrm{~m}$. Two replicas for each testing conditions were performed.

\section{RESULTS AND DISCUSSION}

\section{A. Part Integrity and Microstructure Analysis}

Samples with the designed compositions were successfully produced by SLM using the given process parameters. A view of a set of 316-15CB alloy samples on their build plate is depicted in Figure 2.

Analyses of the as-built alloys revealed that the surface morphology was significantly affected by chemical composition. By exceeding the threshold of 10 pet of CB alloy, the first evidence of balling and irregular solidification tracks was found on SEM views taken from top surface of the samples, as depicted in Figure 3. On the surface of samples containing 20 pct of CB alloy, a few partially molten particles could be detected but the samples remained virtually crack free. On the contrary, part integrity significantly degenerated when exceeding 25 pct of CB alloy, as revealed by shallow surface cracks perpendicular to the laser tracks and by the high amount of balling.

Representative microstructures of the investigated alloys are presented in Figure 4. In Figure 4(a), the microstructure observed from a lateral view (laser tracks are sectioned longitudinally and the vertical axis corresponds to the build direction) of the $316 \mathrm{~L}$ steel processed by SLM is shown at low magnification. It is possible to observe the boundaries of discrete scan tracks and to identify the cellular structure growing epitaxially across several scan tracks, according to 

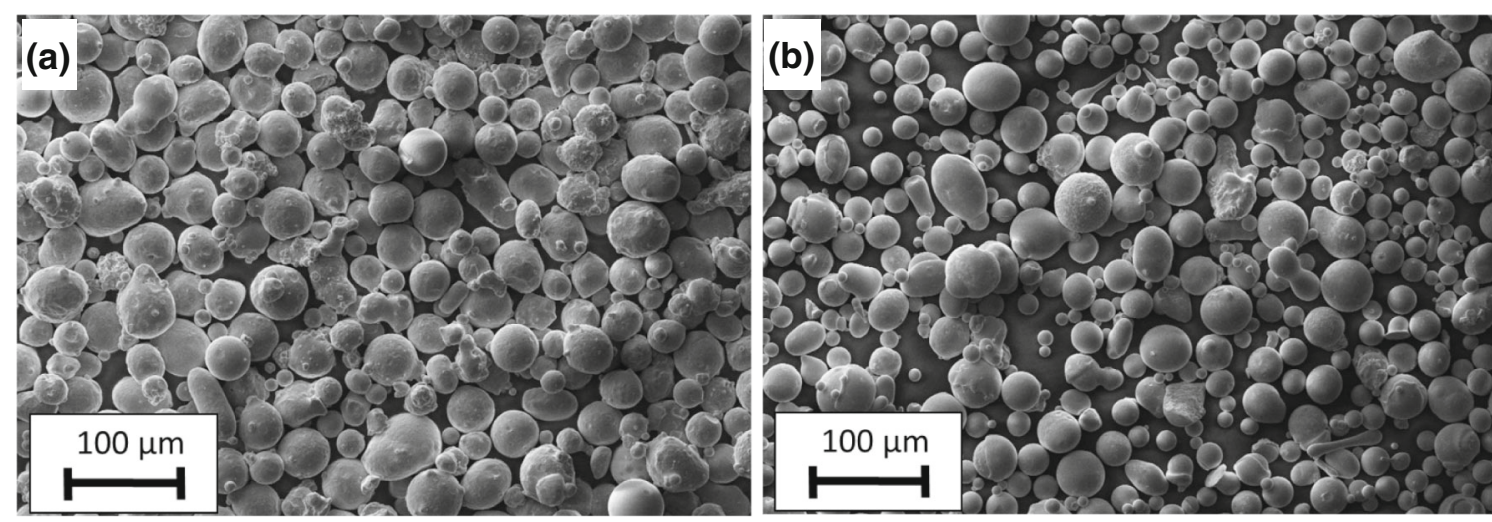

Fig. 1-Morphology of the powder alloys investigated. (a) 316L steel, (b) CB alloy.

Table I. Chemical Compositions (Weight Percent) of the Alloys Investigated

\begin{tabular}{lccccccccccc}
\hline Alloy Code & $\mathrm{C}$ & $\mathrm{Si}$ & $\mathrm{Cr}$ & $\mathrm{Ni}$ & $\mathrm{B}$ & $\mathrm{Mn}$ & $\mathrm{Mo}$ & $\mathrm{V}$ & $\mathrm{Ti}$ & $\mathrm{Nb}$ & $\mathrm{Fe}$ \\
\hline $316 \mathrm{~L}$ & 0.03 & 0.84 & 17.34 & 12.74 & - & 0.85 & 2.27 & - & - & - & bal. \\
CB & 1.96 & 2.94 & 13.32 & 10.89 & 3.68 & 1.14 & - & 0.03 & 0.012 & 0.01 & bal. \\
$316-5 \mathrm{CB}$ & 0.13 & 0.95 & 17.14 & 12.64 & 0.18 & 0.86 & 2.16 & 0.002 & 0.001 & 0.001 & bal. \\
$316-10 \mathrm{CB}$ & 0.22 & 1.05 & 16.93 & 12.55 & 0.37 & 0.88 & 2.04 & 0.003 & 0.001 & 0.001 & bal. \\
$316-15 \mathrm{CB}$ & 0.32 & 1.16 & 16.73 & 12.46 & 0.55 & 0.89 & 1.93 & 0.005 & 0.002 & 0.002 & bal. \\
$316-20 \mathrm{CB}$ & 0.42 & 1.26 & 16.53 & 12.37 & 0.74 & 0.91 & 1.82 & 0.006 & 0.002 & 0.002 & bal. \\
$316-25 \mathrm{CB}$ & 0.51 & 1.37 & 16.33 & 12.27 & 0.92 & 0.92 & 1.70 & 0.008 & 0.003 & 0.003 & bal. \\
\hline
\end{tabular}

Table II. SLM Parameters Adopted for the Processing of the Investigated Materials

Laser Power $P[\mathrm{~W}]$

Focal position $\Delta z[\mathrm{~mm}]$

Scan speed $v[\mathrm{~mm} / \mathrm{s}]$

Hatch spacing $h[\mu \mathrm{m}]$

Layer thickness $t[\mu \mathrm{m}]$

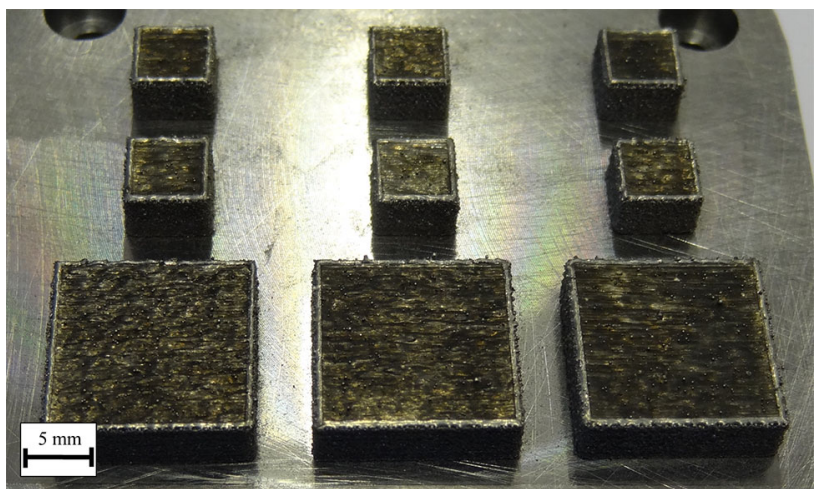

Fig. 2-View of a set of 316-15CB alloy samples produced by SLM.

established solidification mechanisms for SLM. ${ }^{[22-24]}$ When observed on a normal plane (normal to the build direction), the elongated cells are sectioned roughly normal to their growth direction and appear equiaxed, as revealed by the micrograph in Figure 4(b).

The progressive addition of the CB alloy (Figures 4(c) through (e)) led to a reduction in cell size (especially in cell width, as observed from lateral views) and to a partial modification of the cell boundary network structure. Indeed, by increasing the fraction of $\mathrm{CB}$ alloy, the amount of secondary phases at cell boundaries increased and eventually promoted a branching of the boundaries toward the core of the cells, clearly highlighted in Figures 4(d) and (e).

SEM EDX analyses allowed to qualitatively measure the elemental distribution between the core and the boundaries of the cells of the investigated alloys. The microstructure of pure $316 \mathrm{~L}$ featured Ni-rich cells surrounded by a network of $\mathrm{Cr} / \mathrm{Mo}$-rich areas, in full agreement with literature reports. ${ }^{[23]}$ This trend in elemental partitioning was also confirmed in the other investigated alloys. In the $316-20 \mathrm{CB}$ alloy, owing to thicker boundaries, quantitative analyses could be reliably carried out supplying the results given in Table III.

Concurrently, XRD analyses allowed to confirm that the matrix consists of the $\gamma$-Fe phase and that carbides and borides are detectable as second phases. In Figure 5, XRD spectra are given for these second phases extracted from the 316-20CB alloy in the as-built condition and after an annealing treatment at $1150{ }^{\circ} \mathrm{C}$. In both conditions, a main peak corresponding to the $\mathrm{Cr}_{7} \mathrm{C}_{3}$ carbide is identified, whereas $\mathrm{Ti}$ and $\mathrm{V}$ borides $\left(\mathrm{Ti}_{3} \mathrm{~B}_{4}\right.$ and $\mathrm{V}_{2} \mathrm{~B}_{3}$ phases, respectively) are also detectable.

\section{B. DSC Analyses and Thermal Treatments}

DSC heating curves of the $316 \mathrm{~L}, 316-10 \mathrm{CB}$, and 316-20CB alloys are presented in Figure 6 to show phase stability and melting range. Based on similarities with standard wrought austenitic stainless steels ${ }^{[25]}$ and with 

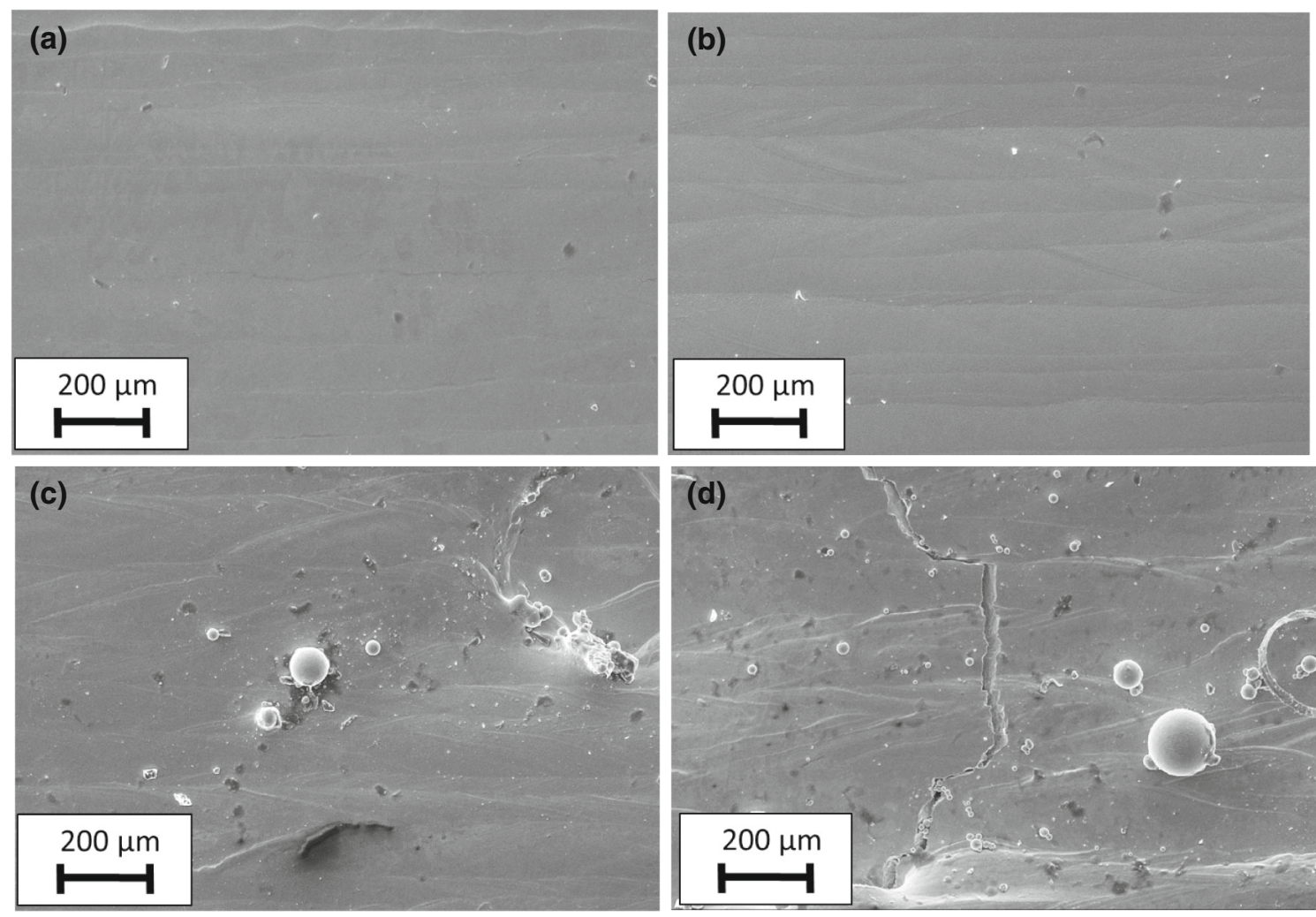

Fig. 3-Selected views of the top surface of SLM processed samples. (a) 316-10CB, (b) 316-15CB, (c) 316-20CB, and (d) 316-25CB alloy.

316L alloy processed by SLM, ${ }^{[26]}$ the peaks observed in the DSC curves could be identified. Two sharp endothermic peaks appear at temperatures of about $1220{ }^{\circ} \mathrm{C}$ and $1420{ }^{\circ} \mathrm{C}$ for the alloy $316 \mathrm{~L}-10 \mathrm{CB}$ and of $1200{ }^{\circ} \mathrm{C}$ and $1350^{\circ} \mathrm{C}$ for the alloy $316-20 \mathrm{CB}$, respectively. Both peaks show evidence of the overlapping of more events. The first set of overlapped peaks is supposed to be related to the dissolution of carbides/borides, whereas the second peak is presumably related to melting process and to partially overlapped-phase transformation occurring immediately before melting of the matrix. ${ }^{[25]}$ The $316 \mathrm{~L}$ alloy showed a smoother DSC curve, featuring a very sharp endothermic melting peak at about $1450^{\circ} \mathrm{C}$.

Annealing treatments were then designed on the basis of the above DSC curves and their effects were investigated considering the tentative temperatures of $1100{ }^{\circ} \mathrm{C}, 1150{ }^{\circ} \mathrm{C}$, and $1200{ }^{\circ} \mathrm{C}$ for a fixed holding period of 1 hour, followed by water quenching. In Figure 7, representative micrographs of the 316-CB alloys after the solution annealing treatments are depicted to highlight the evolution of second-phase morphology.

From micrographs related to $1100{ }^{\circ} \mathrm{C}$ solution annealing (see Figures 7(a) through (c)), it is readily observed that the original cell structure formed after SLM processing is almost fully replaced by a coarser grain structure and that copious re-precipitation of globular-shaped carbides/borides occurred. In the 316-5CB alloy, grain boundaries are still visible (the grain size is estimated to be in the range of 5 to $15 \mu \mathrm{m}$ ), whereas for alloys featuring higher $\mathrm{CB}$ fraction, the dispersion of hard phases fully hides the grain contours.

Higher solution annealing temperatures (compare Figures 7(c) through (e)) selectively dissolved the second-phase particles and eventually led, at $1200{ }^{\circ} \mathrm{C}$, to the coalescence of the precipitates giving rise to a continuous network of carbides/borides at grain boundaries (especially for the 316-10CB and CB-richer alloys). It is also inferred from micrographs that the grain size increased up to several tens of micrometres. The occurrence of precipitation at $1100{ }^{\circ} \mathrm{C}$ and of the gradual dissolution at higher annealing temperatures is consistent with the position of the dissolution peaks observed by DSC (see Figure 6). Relatively low-temperature annealing promotes further precipitation of hardphases, while high-temperature annealing (followed by water quenching) was able to dissolve them.

\section{Hardness Measurements}

Hardness measurements were performed to evaluate the effect of modification of chemical composition and of the annealing treatments. The hardness evolution of the investigated alloys is plotted in Figure 8.

The plot shows that for any material condition, hardness increases almost linearly with the fraction of $\mathrm{CB}$ alloy. The original hardness of the $316 \mathrm{~L}$ alloy in the as-built condition was $208.3 \mathrm{HV}$ and it almost doubled in the 316-25CB alloy, reaching a value of $405.4 \mathrm{HV}$. Solution treatments always reduced the hardness with respect to the corresponding as-built alloys. This is 

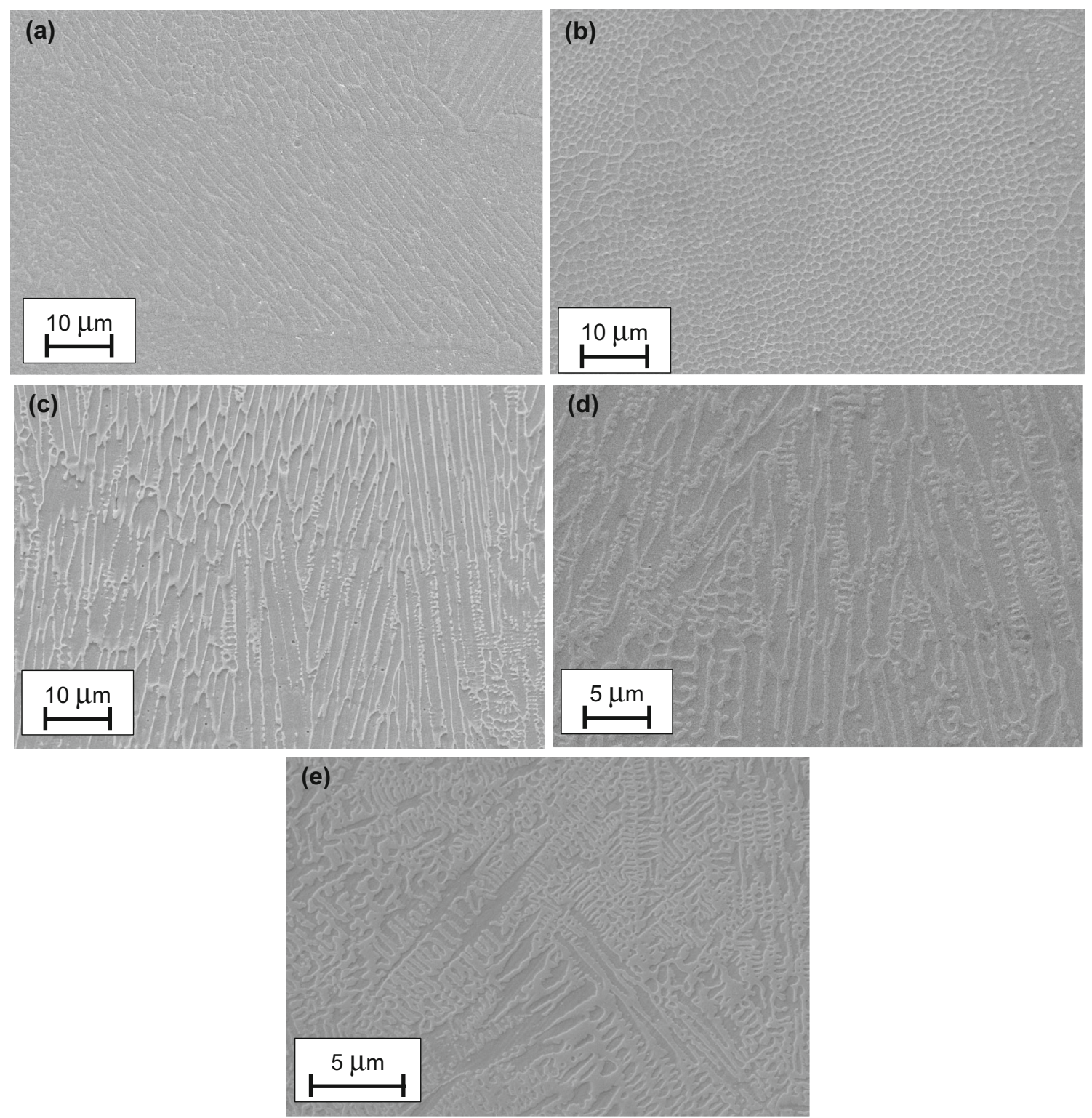

Fig. 4 - Representative micrographs of the investigated alloys. (a) lateral and $(b)$ normal views of $316 \mathrm{~L}$ steel; lateral views of: $(c) 316-5 \mathrm{CB}$, $(d)$ 316-10CB, (e) 316-20CB alloys.

Table III. EDX Composition (Mass Percent) Locally Detected at Cores and Boundaries of the Cells of the 316-20CB Alloy

\begin{tabular}{lcccrr}
\hline & $\mathrm{Si}$ & $\mathrm{Cr}$ & $\mathrm{Mn}$ & $\mathrm{Ni}$ & $\mathrm{Mo}$ \\
\hline Cell core & $1.13 \pm 0.11$ & $16.43 \pm 1.02$ & $0.81 \pm 0.24$ & $12.15 \pm 0.19$ & $1.90 \pm 0.18$ \\
Cell boundaries & $1.36 \pm 0.20$ & $20.04 \pm 0.32$ & $1.11 \pm 0.07$ & $11.23 \pm 0.44$ & $3.98 \pm 0.68$ \\
\hline
\end{tabular}

supposed to be associated to the replacement of the sub-micrometric solidification cell structure with coarser grains after thermal treatment, as observed in the previous section. While the hardness trends for the samples annealed at $1100^{\circ} \mathrm{C}$ and at $1150{ }^{\circ} \mathrm{C}$ were very similar, the samples annealed at $1200{ }^{\circ} \mathrm{C}$ experienced a more significant loss in hardness. This behavior is presumably related to a combination of the extensive grain growth experienced at $1200{ }^{\circ} \mathrm{C}$ and of the different distributions of second phase particles (shift from dispersed particles found in $1100{ }^{\circ} \mathrm{C}$ and $1150{ }^{\circ} \mathrm{C}$ annealed samples to an almost continuous grain boundary network).

\section{Wear Behavior}

Pin-on-disk tests were carried out on as-built and annealed samples. The annealing at $1150{ }^{\circ} \mathrm{C}$ was selected as a reference temperature since it led to the 


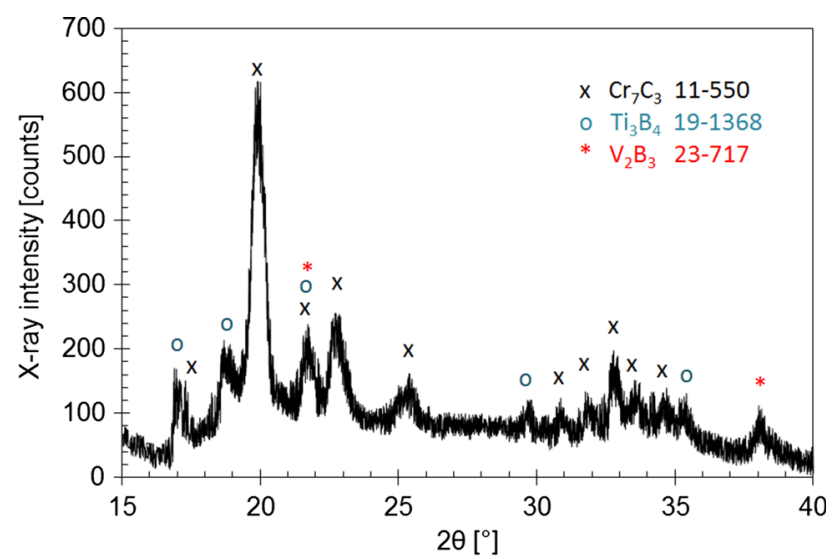

(a)

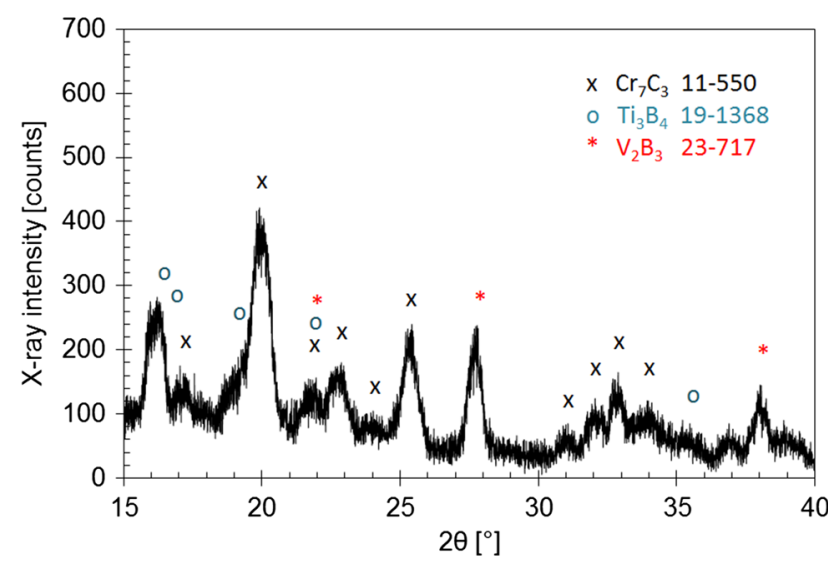

(b)

Fig. 5-XRD spectra recorded on second-phase particles after matrix dissolution for the as-built $(a)$ and the $1150{ }^{\circ} \mathrm{C}$ solution treated (b) 316-20CB alloy.

most intensive precipitation of hard phases, still preventing excessive grain coarsening.

The wear loss of as-built and annealed alloys is plotted in Figure 9. Even though a consistent data scatter is experienced in measured weight-loss data, a clear decreasing trend is observed in wear behavior as a function of fraction of CB alloy. It is also observed that annealed samples exhibit a reduced wear performance due to the already discussed induced softening effect. Based on the wear results, it is inferred that the morphology of the microstructure, which basically could have privileged the more dispersed carbides found in the annealed samples over the continuous network found in the as-built samples, seems to play a minor role on wear resistance, as it does not sufficiently counterbalance the hardness reduction effect related to microstructure coarsening and relaxation of residual stresses induced by the fast solidification and cooling after SLM. ${ }^{[27,28]}$

Selected SEM views of the wear tracks are presented in Figure 10. It is observed that the 316L alloy features extensive plasticity under the pin-on-disk testing condition, with evidence of deep grooves generated by ploughing effects, as expected for this soft steel.

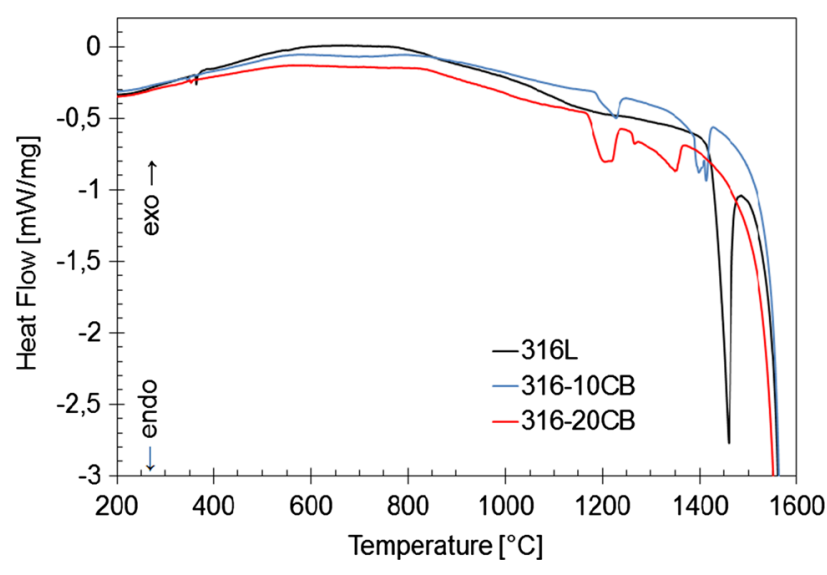

Fig. 6-DSC curves recorded during heating ramps of the $316 \mathrm{~L}$, 316-10CB, and 316-20CB alloys.

Oxidized debris in the form of bright particle aggregates are also noticed on the micrographs. The observed wear mechanisms were substantially similar for both the as-built and annealed 316L samples since the ductile nature of the alloy was always predominant.

When moving to the modified alloys containing significant amounts of hard phases, the wear tracks featured shallower grooves and oxidized debris appear as more dispersed and finer loose particles or clusters, In the most alloyed materials, namely in the $316-20 \mathrm{CB}$ and $316-25 \mathrm{CB}$ alloys, the continuous grooves caused by plastic deformation were mostly replaced by smaller deformation ridges and steps, presumably caused by the discontinuous effects promoted by the hard phases dispersed in the microstructure, and by formation of small craters possibly related to loss of hard particles, or clusters of particles. In these zones, the material was apparently ripped off by the continuous friction exerted by the pin during sliding.

\section{E. Evaluation of the Strengthening Contributions}

From results about hardness evolution and wear behavior, it appears that concurrent strengthening and softening effects are playing important roles on the overall performance of the investigated alloys.

Grain size is the first feature to be considered. From microstructure analyses (see Section III-A), it can be inferred that the cell size of the as-built alloys is in the range 1 to $1.5 \mu \mathrm{m}$ in $316 \mathrm{~L}$ steel and it slightly reduces down to around 0.8 to $1 \mu \mathrm{m}$ for the 316-20CB alloy. Annealing of the alloys resulted in an extensive precipitation of hard phases that prevented the grain boundaries to be accurately identified. However, from data about the $316 \mathrm{~L}$ alloy and the $316-5 \mathrm{CB}$ alloy, it can be evaluated that the grain size increased to about 20, 30, and $50 \mu \mathrm{m}$ for the annealing temperatures of $1100{ }^{\circ} \mathrm{C}$, $1150{ }^{\circ} \mathrm{C}$, and $1200{ }^{\circ} \mathrm{C}$, respectively.

The Hall-Petch relation is a widely acknowledged means for the estimate of the strengthening induced by grain size in several alloys: 

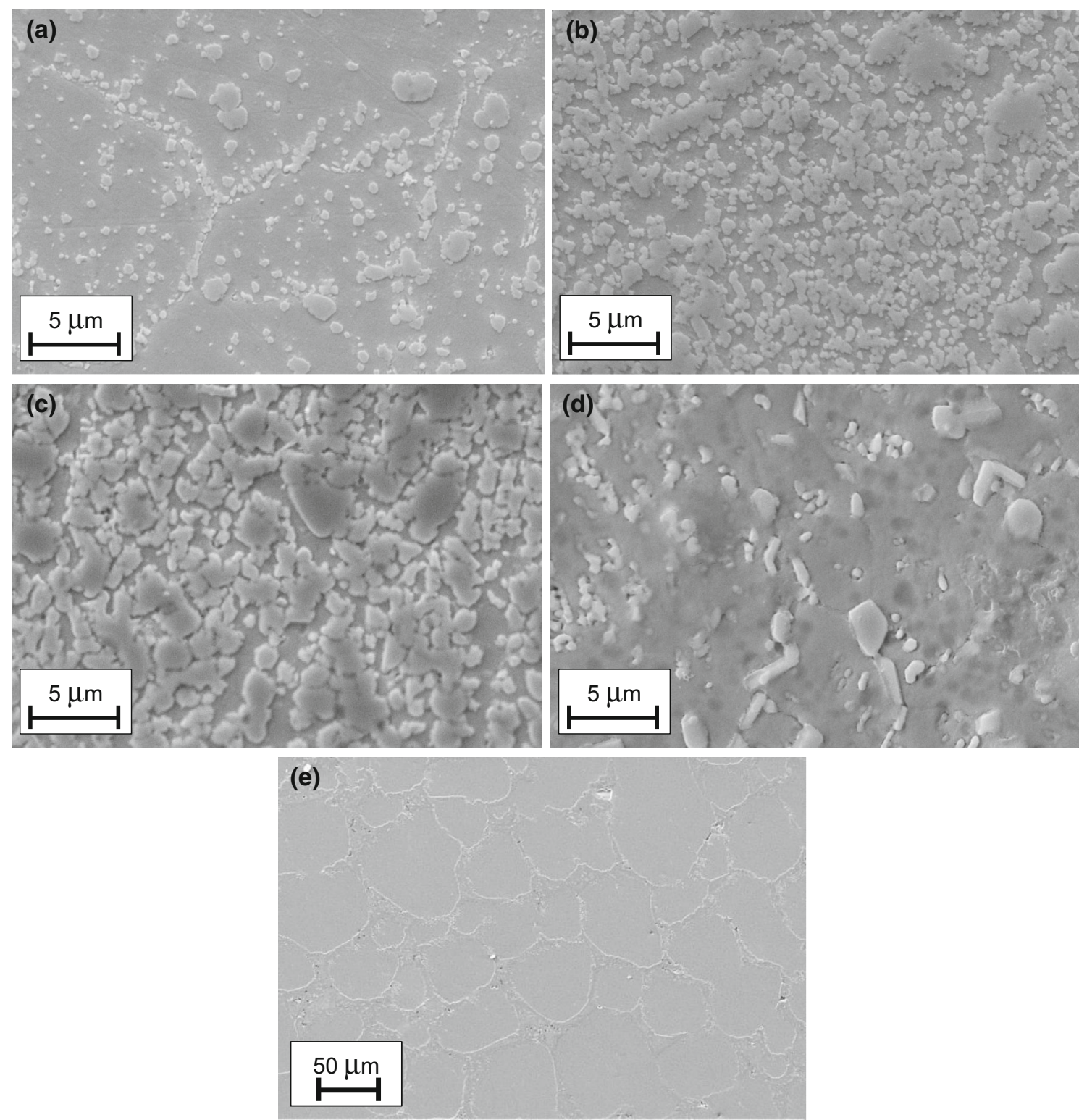

Fig. 7-Representative microstructure of the investigated alloys after solution annealing at $1100{ }^{\circ} \mathrm{C}:($ a) $316-5 \mathrm{CB},($ b) $316-10 \mathrm{CB},(\mathrm{c}) 316-20 \mathrm{CB}$; and for the $316-20 \mathrm{CB}$ alloy after annealing at $(d) 1150{ }^{\circ} \mathrm{C}$ and $(e) 1200{ }^{\circ} \mathrm{C}$.

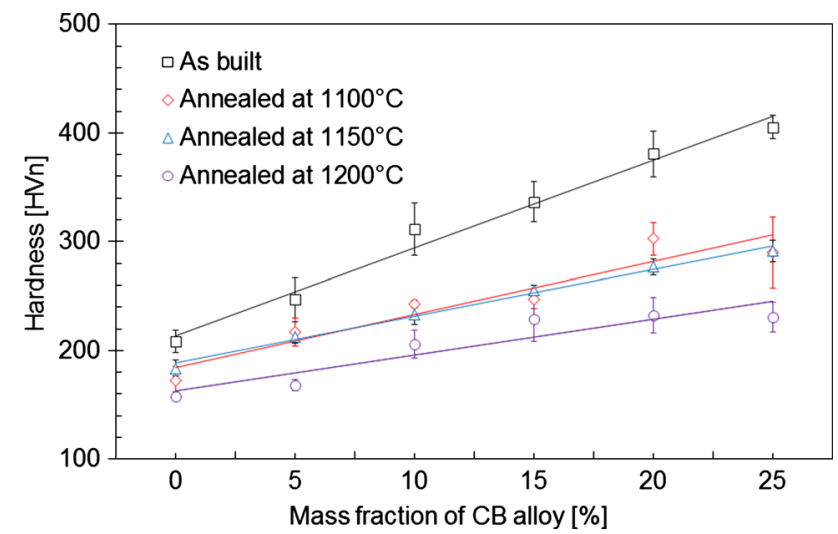

Fig. 8- Hardness evolution of the investigated alloys in as-built and annealed conditions.

$$
\sigma_{y}=\sigma_{0}+k_{\mathrm{HP}} / \sqrt{d},
$$

where $\sigma_{\mathrm{y}}$ is the tensile yield strength; $\sigma_{0}$ is a material constant corresponding to the stress required to dislocation glide; $k_{\mathrm{HP}}$ is the Hall-Petch parameter (depending on material); and $\mathrm{d}$ is the grain size. The validity of the Hall-Petch relation has been recognized for the 316 steel grade, both for conventional and ultrafine grain sizes, ${ }^{[29-31]}$ supplying specific material constants of $\sigma_{0} \approx 200 \mathrm{MPa}$ and $k_{\mathrm{HP}} \approx 700 \mathrm{MPa} / \sqrt{\mathrm{m}}$ for plastic strain values up to 10 pct. ${ }^{[29]}$ It must be specified that hardness is often used instead of the yield strength for the evaluation of the grain-size strengthening. For austenitic steels, the change in yield strength was determined to correspond to the change in hardness times a factor of $3.033^{[32]}$ 
By implementing in Eq. [1] the above material constants and the actual grain sizes, the strengthening effect depicted in Figure 11 is obtained. It is revealed that the Hall-Petch prediction is fairly consistent with measured hardness for the as-built 316L samples, while a clear underestimation is achieved in the annealed samples. This difference is supposed to be due to stresses induced during quenching after annealing and a similar

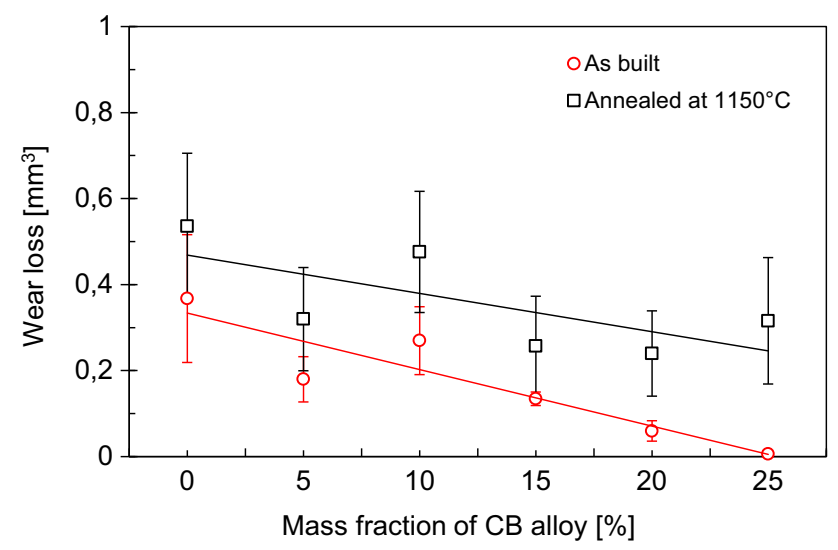

Fig. 9-Wear behavior of the as-built and solution annealed alloys after a sliding distance of $200 \mathrm{~m}$ under pin-on-disk dry sliding condition. gap is reasonably supposed to exist also for the $316-\mathrm{CB}$ alloys.

The second effect that can bring a significant strengthening to the investigated alloys comes from extensive precipitation of hard phases during annealing. Depending on size and shape of the precipitates, several strengthening mechanisms can dominate. ${ }^{[33,34]}$ For carbides and borides in the micrometer range, the main

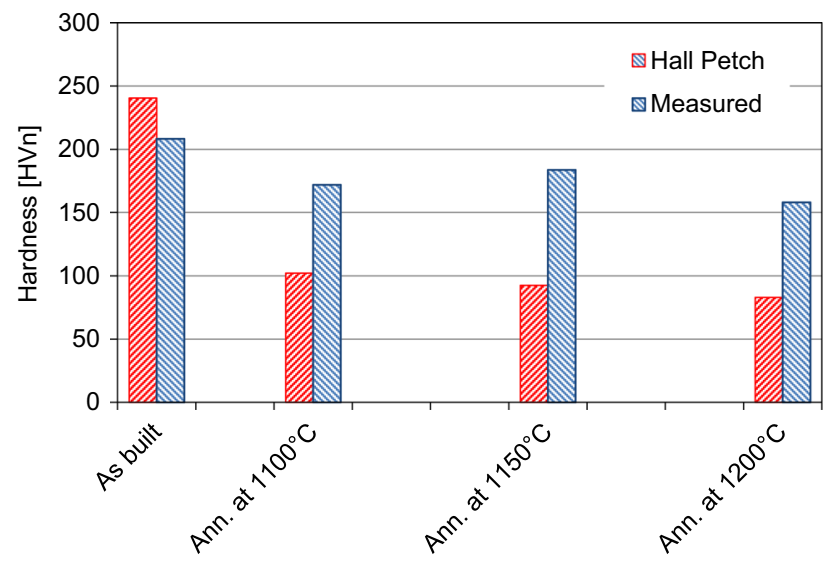

Fig. 11-Comparison between measured and predicted hardness from Hall-Petch relation for the as-built and the solution annealed 316L alloy samples.
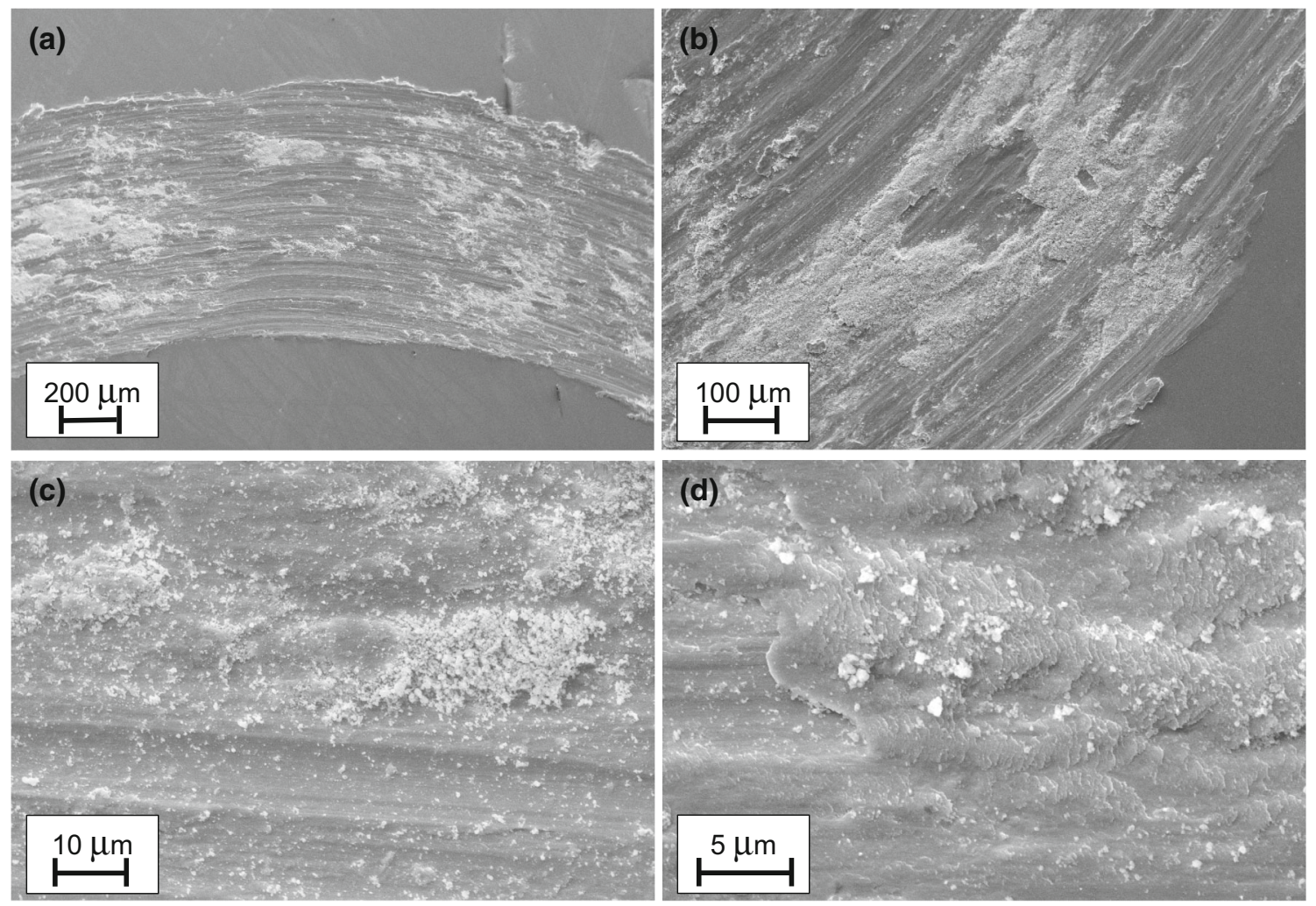

Fig. 10-SEM images of wear tracks of as-built alloys: (a) and (b) 316L, (c) 316-10CB, (d) 316-20CB. 
contribution is expected to come from load transfer effects, supplying a rule-of-mixture (ROM) strengthening law, whereby the achieved strength is the linear contribution of the matrix and particle strength values weighted by their volume fraction. Alternatively, for sub-micrometric size precipitates, the Orowan strengthening, accounting for the interaction of precipitates with dislocations should prevail.

The overall combination of the different effects induced by particle strengthening has been considered for instance in a paper by Zhang and Chen focussed on metal matrix nanocomposites. ${ }^{[3]}$ Their analytical model, which was validated by literature data, clearly showed that in addition to volume fraction of the second phases, an increased strength could be achieved by decreasing the size of the particles.

The linear trend of hardness depicted in Figure 8 confirms that strengthening depends on the fraction of hard phases accepting the hypothesis that the amount of hard phases could be, to a first approximation, proportional to amount of carbide- and boride-forming elements added through the CB alloy. The present results show that this behavior holds for each temper investigated, in full agreement with the ROM law.

However, a careful observation of all the data given in Figure 8 also suggests that the slope of hardness for as-built materials vs amount of CB alloy is clearly higher than the corresponding slopes of the solution annealed materials, showing that particle strengthening is more effective in as-built materials than in solution annealed alloys. An explanation for this behavior can be found in the different sizes and distributions of the hard precipitates in these two tempers. Indeed, as-built alloys feature a fine distribution of intercellular phases having a sub-micrometric size that are believed to be more effective in inducing a strengthening contribution than the relatively coarse phases found in the solution annealed samples.

When drawing conclusive guidelines about the design of particle-strengthened steels to be processed by SLM, from results achieved in present investigation it can be suggested that the optimal microstructure for a $316 \mathrm{~L}$ stainless steel modified by the addition of carbide/boride-forming elements is achieved right after SLM processing (as-built condition), featuring the finest cellular structure with a distribution of sub-micrometric hard phases. Attempts to modify the as-built precipitate configuration by high-temperature solution annealing treatments, possibly increasing their volume fraction and modifying their distribution, led to a net loss of hardness (and consequently of wear behavior) owing to predominant effects brought by grain growth and by extensive coarsening of the precipitates. The expected strengthening contribution induced by carbide/borides, which was verified to linearly depend on the fraction of these hard phases, plays a minor role on overall strengthening.

Finally, it could be argued that a more controlled precipitation of finer hard particles could have been alternatively achieved by low-temperature annealing treatments (i.e., in the range $500{ }^{\circ} \mathrm{C}$ to $900{ }^{\circ} \mathrm{C}$ ), allowing finer particles to be formed while preventing significant grain growth. Further investigations are in progress on this subject, even if it has to be considered that embrittlement related to sigma phase formation and to grain boundary sensitization could possibly worsen the general frame of properties. ${ }^{[35]}$

\section{CONCLUSIONS}

In this research work, novel austenitic alloys have been designed, produced and tested by blending a standard 316L stainless steel with a special modifier alloy (CB alloy) containing $\mathrm{C}, \mathrm{B}$, and several carbide forming elements $(\mathrm{Cr}, \mathrm{V}, \mathrm{Ti}, \mathrm{Nb})$. The blended powders were then successfully consolidated by SLM. The following achievements have been reached by investigating the experimental alloys.

The 316L stainless steel could be alloyed by significant amounts of carbide- and boride-forming elements and successfully processed by SLM. A fraction of 20 pct of $\mathrm{CB}$ alloy was found to be the upper threshold value at which high integrity parts free from macro cracks could be produced. For this fraction, the resulting $\mathrm{C}$ content was 0.42 pct and the $B$ content was 0.74 pct.

The progressive addition of CB alloy led to an almost linear increase in hardness after SLM processing. Hardness increased from 208.3 HV (316L steel) up to 380.7 HV (316-20CB alloy) in the as-built condition, corresponding to an increase of 82.7 pct. Strengthening by hard particle contribution was therefore found to be governed by a rule-of-mixture.

Heat treatments consisting of annealing and water quenching at different temperature levels were considered to modify the microstructure, shifting from fine austenitic cells surrounded by a hard-phase network to a homogeneous dispersion of spheroidal carbide/borides within coarser austenitic grains. Annealing up to $1150{ }^{\circ} \mathrm{C}$ allowed to promote precipitation, reaching the expected microstructure. On the contrary, samples subjected to $1200{ }^{\circ} \mathrm{C}$ annealing experienced partial dissolution of the hard phases, extensive grain coarsening and the achievement of an almost continuous network of hard phases at grain boundaries.

The assessment about the most effective strengthening mechanism achievable in the investigated alloys showed that the small cell size (in the range 0.8 to $1.5 \mu \mathrm{m}$ ) and the distribution of the sub-micrometric hard phases located at cell boundaries in the as cast materials represents the best microstructural condition. Alternative attempts aimed at improving the distribution of carbides and borides and at increasing their volume fraction by annealing treatments revealed to be ineffective owing to concurrent coarsening of grain and particle sizes.

Wear resistance of the investigated alloys increased linearly with the fraction of CB alloy and showed a clear dependence on achieved hardness. When moving from as-built $316 \mathrm{~L}$ steel to $316-20 \mathrm{CB}$ alloy, the wear resistance could be increased by a factor of 6 . 


\section{ACKNOWLEDGMENTS}

This research work was partially funded by Regione Lombardia (Italy).

\section{REFERENCES}

1. M.Y. Demeri: Advanced High-Strength Steels - Science, Technology, and Application, ASM International, Ohio, $\mathrm{OH}, 2013$.

2. J.W. Simmons: Mater. Sci. Eng. A, 1996, vol. 207, pp. 159-69.

3. H. Sieurin, J. Zander, and R. Sandström: Mater. Sci. Eng. A, 2006, vol. 415 , pp. 66-71.

4. H.C. Shin, T.K. Ha, and Y.W. Chang: Scripta Mater., 2001, vol. 45 , pp. 823-29.

5. I.I. Kositsyna: Met. Sci. Heat Treat., 2008, vol. 50, pp. 459-67.

6. K. Tokaji, T. Horie, and Y. Enomoto: Int. J. Fatigue, 2006, vol. 28 , pp. 281-88.

7. V. Kuzucu, M. Aksoy, and M.H. Korkut: J. Mater. Process. Technol., 1998, vol. 82, pp. 165-71.

8. M. Kulka, A. Pertek, and L. Klimek: Mater. Charact., 2006, vol. 56, pp. $232-40$.

9. I. Mejía, A. Bedolla-Jacuinde, C. Maldonado, and J.M. Cabrera: Mater. Sci. Eng. A, 2011, vol. 528, pp. 4468-74.

10. W.E. Frazier: J. Mater. Eng. Perform., 2014, vol. 23, pp. 1917-28.

11. W.J. Sames, F.A. List, S. Pannala, R.R. Dehoff, and S.S. Babu: Int. Mater. Rev., 2016, vol. 61, pp. 315-60.

12. W.E. King, A.T. Anderson, R.M. Ferencz, N.E. Hodge, C. Kamath, S.A. Khairallah, and A.M. Rubenchik: Appl. Phys. Rev., 2015, vol. 2, pp. 041304-1-041304-26.

13. J.P. Kruth, L. Froyen, J. Van Vaerenbergh, P. Mercelis, M. Rombouts, and B. Lauwers: J. Mater. Process. Technol., 2004, vol. 149 , pp. 616-22.

14. J.A. Cherry, H.M. Davies, S. Mehmood, N.P. Lavery, S.G.R. Brown, and J. Sienz: Int. J. Adv. Manuf. Technol., 2015, vol. 76, pp. 869-79.

15. D. Wang, C. Song, Y. Yang, and Y. Bai: Mater. Des., 2016, vol. 100, pp. 291-99.

16. R. Casati, J. Lemke, and M. Vedani: J. Mater. Sci. Technol., 2016, vol. 32 , pp. $738-44$.
17. E.J. Pavlina and C.J. Van Tyne: J. Mater. Eng. Perform., 2008, vol. 17, pp. 888-93.

18. F. Feuerhahn, A. Schulz, T. Seefeld, and F. Vollertsen: Phys. Procedia, 2013, vol. 41, pp. 843-48.

19. J. Sander, J. Hufenbach, L. Giebeler, H. Wendrock, U. Kühn, and J. Eckert: Mater. Des., 2016, vol. 89, pp. 335-41.

20. M.J. Holzweissig, A. Taube, F. Brenne, M. Schaper, and T. Niendorf: Metall. Mater. Trans. B, 2015, vol. 46B, pp. 545-49.

21. M.A. Taha, A.F. Yousef, K.A. Gany, and H.A. Sabour: Mater. Wiss. Werkst., 2013, vol. 43, pp. 913-23.

22. T. Niendorf, S. Leuders, A. Riemer, H.A. Richard, T. Tröster, and D. Schwarze: Metall. Mater. Trans. B, 2013, vol. 44B, pp. 794-96.

23. L. Thijs, K. Kempen, J.-P. Kruth, and J. Van Humbeeck: Acta Mater., 2013, vol. 61, pp. 1809-19.

24. M. Ziętala, T. Durejko, M. Polański, I. Kunce, T. Płociński, W. Zieliński, M. Łazińska, W. Stępniowski, T. Czujko, K.J. Kurzydłowski, and Z. Bojar: Mater. Sci. Eng. A, 2016, vol. 677, pp. $1-10$.

25. D.S. Petrovic, G. Klancnik, M. Pirnat, and J. Medvet: J. Thermal Anal. Calorim., 2011, vol. 105, pp. 251-57.

26. K.O. Bazaleeva, E.V. Tsvetkova, E.V. Balakirev, I.A. Yadroitsev, and I.Y. Smurov: Russ. Metall. (Metally), 2016, vol. 5, pp. $424-30$.

27. P. Mercelis and J.-P. Kruth: Rapid Prototyp. J., 2006, vol. 12, pp. 254-65.

28. Y. Liu, Y. Yang, and D. Wang: Int. J. Adv. Manuf. Technol., 2016, vol. 87 , pp. $647-56$.

29. X. Feaugas and H. Haddou: Metall. Mater. Trans. A, 2003, vol. 34A, pp. 2329-40.

30. G. Marnier, C. Keller, J. Nouderm, and E. Hug: Mater. Des., 2014, vol. 63, pp. 633-40.

31. O. Takakuwa, Y. Kawaragi, and H. Soyama: J. Surf. Eng. Mater. Adv. Technol., 2013, vol. 3, pp. 262-68.

32. J.T. Busby, M.C. Hash, and G.S. Was: J. Nuclear Mater., 2005, vol. 336, pp. 267-78.

33. R. Casati and M. Vedani: Metals, 2014, vol. 4, pp. 65-83.

34. Z. Zhang and D.L. Chen: Scripta Mater., 2006, vol. 54, pp. 1321-26.

35. C.C. Hsieh, W. Wu: ISRN Metallurgy, 2012. https://dx.doi.org/ $10.5402 / 2012 / 732471$. 